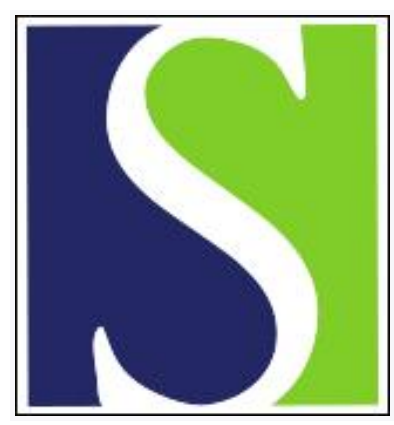

Scand J Work Environ Health 1977;3(1):23-27

https://doi.org/10.5271/sjweh.2795

Issue date: Mar 1977

Endurance limit of force in long-term intermittent static contractions.

by Björkstén $M$, Jonsson $B$

Key terms: endurance; endurance limit; fatigue; force; static contraction

This article in PubMed: www.ncbi.nlm.nih.gov/pubmed/847427

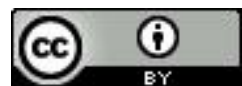




\title{
Endurance limit of force in long-term intermittent static contractions
}

\author{
by MARIANNE BJÖRKSTÉN, physical therapist, and
} BENGT JONSSON, M.D. ${ }^{1}$

\begin{abstract}
BJÖRKSTÉN, M. and JONSSON, B. Endurance limit of force in long-term intermittent static contractions. Scand $j$. work environ. \& health 3 (1977) 23-27. The relationship between endurance time and the mean force of contraction was investigated in intermittent and sustained static contractions over a long period of time $(60 \mathrm{~min})$. For intermittent static contractions the endurance limit of the mean force of contraction was found to be $14.0 \%$, and for sustained static contractions it was $7.9 \%$ of the maximal force of contraction. Weak subjects appear to have a higher endurance limit of force than strong subjects.
\end{abstract}

Key words: endurance, fatigue, static contractions.

Work processes which demand repeated intermittent static contractions or intermittent dynamic work with small angular movements of the joints are fairly common in industry. The periods of contraction, as well as the intervening periods of rest, are often short with durations of a few seconds.

According to Rohmert $(6,7)$ the endurance limit of force in a static contraction is $15 \%$ of the maximal voluntary force of contraction (MVC) of the muscle, the endurance limit then being defined as the highest force the muscle can maintain for an "unlimited" period of time without reduction of the force. In Rohmert's investigations this "unlimited" period of time was set at 10-15 min. Rohmert showed that there is an exponential relationship between the maximal endurance time and

1 Work Physiology Division, Department of Occupational Medicine, National Board of Occupational Safety and Health, Umeå Hospital, Umeå, Sweden.

Reprint requests to: Dr. Bengt Jonsson, Arbetarskyddsstyrelsen, Arbetsmedicinska avdelningen, Arbetsfysiologiska enheten i Umeå, Regionsjukhuset, S-901 85 Umeå, Sweden. the force of concentration in static contractions. Considering the fact that there are differences in the MVC, he also claimed that there is no difference in endurance. Caldwell (1) reported that, when the loading was expressed as a percentage of the individual MVC, no differences in endurance time between different subjects were found. In opposition Kroll (3) found a significant difference in endurance time between subjects with a high or medium MVC level on one hand and those with a low MVC level on the other. In the latter group fatigue developed more slowly. Kroll's report was supported by Mundale (5), who found that weaker subjects seem to be able to maintain endurance activities at a higher proportion of the MVC than stronger subjects.

The aims of the present study were to investigate the relationship between endurance time and the mean force of contraction in intermittent static contractions and to study how the duration of the periods of contraction and the intervening periods of rest influence the endurance time of work. The experiments were conducted in 1-h periods so that a meaningful endurance limit for the mean force 
Table 1. Data on the eight subjects who participated in the individual tests.

\begin{tabular}{|c|c|c|c|c|c|c|c|c|}
\hline & \multicolumn{4}{|c|}{ Males } & \multicolumn{4}{|c|}{ Females } \\
\hline & 28 years & 37 years & 26 years & 36 years & 21 years & 30 years & 35 years & 34 years \\
\hline $\begin{array}{l}\text { Maximal voluntary } \\
\text { contraction (Newton) }\end{array}$ & 343 & 343 & 338 & 324 & 216 & 213 & 186 & 157 \\
\hline Static contractions & $x$ & $x$ & $x$ & $x$ & $x$ & $x$ & $x$ & $x$ \\
\hline $\begin{array}{l}\text { Combinations of } \\
\text { work and rest }\end{array}$ & & & & & & & & \\
\hline $\begin{array}{l}9+1 s \\
8+2 s\end{array}$ & & $\begin{array}{l}x \\
x\end{array}$ & & & $\begin{array}{l}x \\
x\end{array}$ & & $\begin{array}{l}x \\
x\end{array}$ & \\
\hline $\begin{array}{l}7+3 s \\
6+4 s\end{array}$ & $x$ & $\begin{array}{l}x \\
x\end{array}$ & $\begin{array}{l}\times \\
x\end{array}$ & $x$ & $\begin{array}{l}x \\
x\end{array}$ & $x$ & $\begin{array}{l}x \\
x\end{array}$ & $x$ \\
\hline $\begin{array}{l}5+5 s \\
4+6 s\end{array}$ & x & $\begin{array}{l}x \\
x\end{array}$ & $x$ & $x$ & $x$ & $x$ & $x$ & $x$ \\
\hline $\begin{array}{l}3+7 \mathrm{~s} \\
2+8 \mathrm{~s} \\
1+9 \mathrm{~s}\end{array}$ & $x$ & $\begin{array}{l}x \\
x \\
x\end{array}$ & $x$ & $x$ & $x$ & $x$ & $\begin{array}{l}x \\
x \\
x\end{array}$ & $x$ \\
\hline
\end{tabular}

of contraction over a defined period of time could be calculated.

\section{MATERIAL AND METHODS}

The experiments were performed on eight healthy subjects ( 4 males and 4 females) aged $21-37$ years. They all belonged to the university staff, and their physical activity can be described as moderate or low.

The tests consisted of constant or intermittent contractions of the elbow flexors with a load applied to the hand. All subjects were right-handed and in all cases the right arm was examined. The maximal force of the right elbow flexors as measured at the hand was $157-343 \mathrm{~N}$ with a mean of $265 \mathrm{~N}$ (337 $\mathrm{N}$ for the males and $193 \mathrm{~N}$ for the females).

During the experiments the subjects were standing or sitting with the upper arm vertical and held against a wall with the elbow in $90^{\circ}$ of flexion and with the forearm in semipronation. The hand was holding a dumbbell with a weight of $1,2,3,4$, $5,6,7,8,9,10,12.5,15,17.5,20,22.5$ or 25 kg. During the rest periods the dumbbell was supported by a bench beside the subject at the elbow level. During the periods of contraction the subjects had to elevate the dumbbell a few centimeters above the bench. They performed this slight movement mainly by elevating the shoulder while at the same time keeping the elbow angle constant at $90^{\circ}$.

An audiovisual timing mechanism indicated to the subject when he was to elevate or lower the dumbbell and thereby contract or relax the elbow flexors, respectively. The total contraction/relaxation cycle was kept constant at $10 \mathrm{~s}$ in this investigation. The combinations of the durations of the contraction and relaxation periods (contraction + relaxation) used were $9+1,8+2,7+3,6+4,5+5$, $4+6,3+7,2+8$ and $1+9$ s. In addition purely static contractions without rest periods were studied. The subject was instructed to continue the intermittent elevation of the dumbbell or the static contraction as long as possible. An upper time limit however was set at $60 \mathrm{~min}$. When the subject was able to continue for more than $60 \mathrm{~min}$ at a specific load and contraction/relaxation combination, all lower loads at that combination, as well as the actual load and all lower loads in all combinations with longer periods of relaxation were excluded from the test program of that subject. To diminish the effects of training, the subjects performed the tests in a random order. However at lower loads and longer periods of relaxation higher loads were used before lower loads at one and the same combination of contraction/relaxation, or shorter periods of relaxation came before longer ones at one and the same load. The subjects were 
not allowed to perform more than four tests on a single day, and the whole study was extended over an 8-month period of time.

Two of the eight subjects completed the whole test program (table 1). All the remaining subjects were tested with static contractions and the combinations $7+3$, $5+5$, and $3+7$. One subject also performed the combinations $9+1,8+2$ and $6+4$, and another the combination $6+4$.

The relative force of contraction, expressed as the percentage of the MVC, was calculated for each external load tested for each subject. The relative mean force of contraction in intermittent static contractions was then calculated as the time mean of the relative force of contraction; i.e., the relative force of contraction was multiplied by the relative duration of the periods of contraction. For example, when a load representing $20 \%$ of the MVC at the combination $7+3(70 \%$ of the total time) was used, the mean force was $20 \times$ $0.7=14 \%$ of the MVC.

\section{RESULTS}

The results obtained during static contractions and during the combinations $7+3,5+5$, and $3+7$ of work and rest with all eight subjects are presented in fig. 1 and table 2 . The magnitude of the relative force of contraction varied from 5.5 to $60 \%$ of the MVC. The mean endurance limit of force for $60 \mathrm{~min}$ of static contraction was as low as $7.9 \%$ of the MVC (6.9 \% for the males and $8.9 \%$ for the females). The mean endurance limit of the mean force of contraction for $60 \mathrm{~min}$ of intermittent static contractions was almost twice as high with a mean of $14.0 \%$ of the MVC (11.6 \% for the males and $16.3 \%$ for the females) for the combinations $7+3$, $5+5$, and $3+7$. At a low mean force of contraction there was a significant difference in the endurance limit of force between continuous and intermittent static contractions when analyzed by the "Student's" t-test $\left(t_{\text {dep }}\right.$ 0.01). No such difference was found between different combinations of work and rest periods in intermittent contractions. When the endurance time was evaluated at a high mean force of contraction, no significant differences were found between static contractions and different intermittent contractions.

The results obtained from one of the subjects who performed the whole test program are given in fig. 2. The combinations $9+1$ and $1+9$ of work and rest clearly differed from the other combinations and approached results similar to those obtained during purely static contractions.

Differences in the endurance limit of force and in the power function for the relationship between force and endurance time was found between the males (strong subjects) and the females (weak subjects)

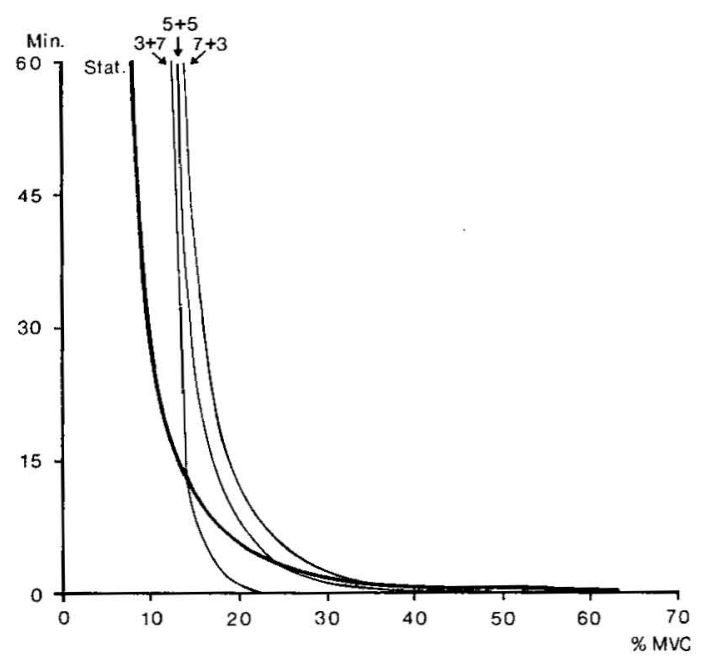

Fig. 1. Endurance time for static and three combinations of intermittent static contractions $(7+3,5+5$ and $3+7 \mathrm{~s})$ as a function of the mean force of contraction expressed as the percentage of MVC. The median values for all eight subjects have been used.

Table 2. Mean values of endurance limits of force in percentage of $\mathrm{MCV}$ for $60 \mathrm{~min}$ of work in different combinations of work and rest.

\begin{tabular}{lcccc}
\hline \multirow{2}{*}{$\begin{array}{l}\text { Subjects } \\
\text { tested }\end{array}$} & Static & \multicolumn{3}{c}{ Work plus rest (s) } \\
\cline { 2 - 5 } & & $7+3$ & $5+5$ & $3+7$ \\
\hline Males (4) & 6.9 & 11.6 & 11.9 & 11.2 \\
Females (4) & 8.9 & 18.1 & 15.9 & 14.9 \\
\hline Total (8) & 7.9 & 14.9 & 13.9 & 13.1 \\
\hline
\end{tabular}




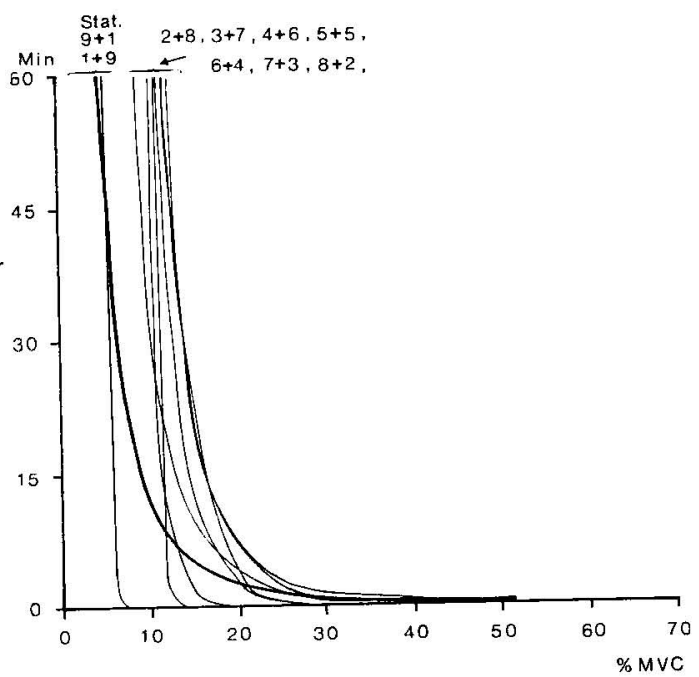

Fig. 2. Endurance time for static and nine different intermittent static contractions as a function of the mean force of contraction expressed as the percentage of MVC for one subject (subject 2).

as indicated in table 2 and fig. 3. These differences were not statistically significant however.

\section{DISCUSSION}

The present results indicate that the endurance limit of force for $60 \mathrm{~min}$ of static contraction is approximately $8 \%$ of the maximal force of contraction for the elbow flexors. This limit is almost half the $15 \%$ limit found by Rohmert $(6,7)$. The difference may be explained by the fact that Rohmert assumed that a static contraction which can be sustained for $10-15 \mathrm{~min}$ can be sustained for an "unlimited" period of time. In accordance with Rohmert our results indicate that the endurance limit of force for $10 \mathrm{~min}$ of static contraction is close to $15 \%$ of the maximal force of contraction.

The endurance limit of the mean force of contraction for $60 \mathrm{~min}$ of intermittent static contractions was significantly higher (14 \% of MVC) than that for purely static contractions. The endurance limit of the mean force for intermittent static contractions was the highest when the duration of the periods of rest in proportion to the total time was $30 \%(7+3)$; this figure is close to what Müller (4) considered optimal. There were, however, no significant differences between the different combinations of work and rest in intermittent static contractions with respect to the 60-min endurance limit of the mean force of contraction. The endurance limit of the mean force became lower as the total duration of work decreased, i.e., with higher forces of contraction. One reason is that the endurance time of contraction decreases exponentially as the force of contraction increases. This phenomenon may have an effect on the total endurance time in those cases in which the muscle must contract almost maximally in order to create a low or moderate mean force of contraction. In those cases in which the duration of the periods of work was as low as $10 \%$ of the total duration of work + rest, the mean force of contraction could of course never exceed $10 \%$ of the MVC. Therefore the curve representing the combination $1+9$ in fig. 2 differs from the other combinations and approximates the curve of purely static contractions. The $9+1$ combination in fig. 2 also approximates the curve of static contractions probably because the $1 \mathrm{~s}$ of rest is not enough time to get a complete

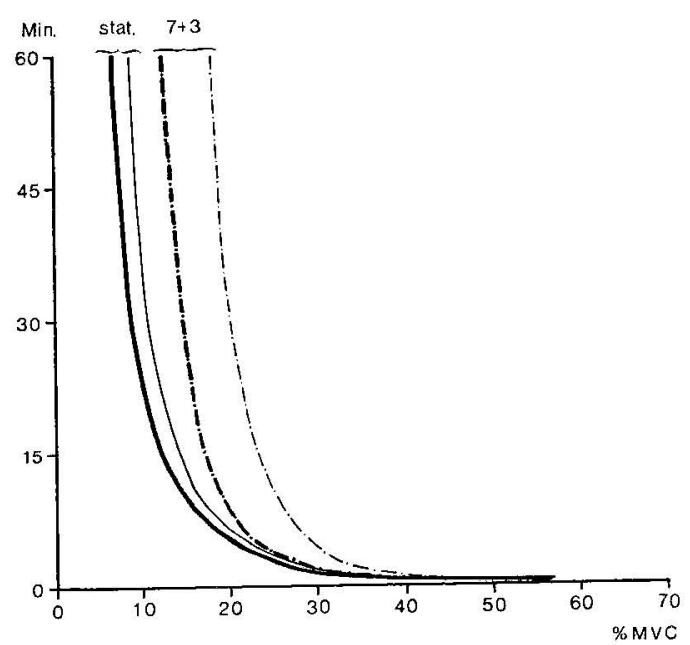

Fig. 3. Endurance time for static and one combination of intermittent static contractions $(7+3)$ as a function of the mean force of contraction expressed as the percentage of MVC. The median values for males (thick lines) and females (thin lines) have been used. 
relaxation of the muscle, and thus the $9+1$ combination is almost like a static contraction.

Individual differences in the shape of the regression lines were observed for the relation between endurance time and the mean force of contraction. The females tended to show a higher endurance limit of force than the males, particularly in long sustained intermittent contractions. The present material was, however, too small to allow any conclusions about the reasons for these interindividual differences. Kroll (3) and Mundale (5) concluded that subjects with low MVC levels fatigued more slowly, and the results obtained in this investigation would possibly support this view. The explanation for the interindividual differences observed may be interindividual differences in the distribution of slow and fast twitch fibers in the muscle. This assumption is supported by Hultén et al. (2), who found a linear relationship between isometric endurance performance at $50 \%$ of the MVC and skeletal muscle fiber composition as the percentage of slow twitch muscle fibers. Another explanation may be differences in intramuscular pressure between strong and weak subjects. If the intramuscular pressure is proportional to the absolute force of contraction and if the blood pressure is the same in a strong and a weak subject, the blood perfusion through the weaker subject's muscle would be better at a given relative force of contraction.

The practical application of the present investigation is that the endurance limit of force for 10-15 min of static contraction, which is known to be approximately $15 \%$ of the MVC, cannot be used as an acceptable upper limit of force for "continuous" static contractions. The upper limit for $1 \mathrm{~h}$ of contraction is approximately $8 \%$ of the MVC, and the acceptable upper limit of force for a "continuous" $(4-8 \mathrm{~h})$ contraction is probably as low as a few per cent of the MVC. Therefore purely static contractions should never be accepted in a work process no matter how weak the contraction is. As soon as there are intermittent contractions with repeated short periods of rest, there is a marked increase in the endurance limit of the mean force of contraction. The endurance time in intermittent contractions is a function of the mean relative force of contraction. Therefore an increase in the relative force of the contractions can be compensated by a proportional decrease in the relative duration of the periods of contraction; i.e., the duration of the rest periods between the individual contractions can be increased or the duration of the periods of contraction can be decreased.

\section{ACKNOWLEDGMENT}

This investigation was supported by grants from the Swedish Work Environment Fund (project no. 73/23) and the Swedish Medical Research Council (project no. $12 \mathrm{X}-2711$ ).

\section{REFERENCES}

1. CALDWELL, L. S. Relative muscle loading and endurance. J. eng. psychol. 21 (1963) $155-161$.

2. HULTÉN, B., THORSTENSSON, A., SJÖDIN, B. and KARLSSON, J. Relationship between isometric endurance and fibre types in human leg muscles. Acta physiol. scand. 93 (1975) 135-138.

3. KROLL, W. Isometric fatigue curves under varied intertrial recuperation periods. Res. q. 39 (1968) 106-115.

4. MÚlLER, 1935. Quoted by Simonson, E. Physiology of work capacity and fatigue. Charles C. Thomas, Springfield, Ill. 1971, p. 251.

5. MUNDALE, M. O. The relationship of intermittent isometric exercise to fatigue of hand grip. Arch. phys. med. rehabil. 51 (1970) $532-539$.

6. ROHMERT, W. Ermittlung von Erholungspausen für statische Arbeit des Menschen. Int. Z. Angew. Physiol. Einschl. Arbeitsphysiol. 18 (1960) 123-169.

7. ROHMERT, W. Problems in determining rest allowances: Part 1. Use of modern methods to evaluate stress and strain in static muscular work. Appl. ergon. 4.2 (1973) $91-95$. 